\title{
The Journal of the American Medical Association
}

Published under the Auspices of the Board of Trustees

Volume LIII CHICAGO, ILLINOIS, AUG. 14, 1909 Number 7

\section{Addresses}

\section{WHAT THE INDIVIDUAL PHYSICIAN CAN DO TO IMPROVE THE MATERIA MEDICA *}

REID HUNT, M.D.

Chlef, Division of Pharmacology, Hygienic Laboratory, U. S. Public Health and Marine-Hospital Service WASHINGTON, D. C.

The subject of this address is, I believe, one of much importance to the physician, both as an individual and as a member of a learned and dignified profession, but a profession which has allowed itself to be imposed on and permitted even its dignity to be lowered and its usefulness lessened by certain influences both within and without. So much has been said in recent years on the subject of proprietary medicines that I might hesitate to bring it up again if the times did not seem so opportune for constructive work, and work in which the individual physician can and must take the leading part.

Before entering on this discussion, however, a few words may be said concerning the place of drug therapeutics in the practice of medicine. The best energies of the profession for almost a generation have been devoted to the discovery of the causes, and methods for the prevention, of disease, and to the development of surgical technic and to the improvement of diagnosis; the greatest successes have been achieved in these directions. These developments have concerned the public and certain specialties rather more directly than the general practitioner who is confronted with concrete and individual cases. The individual patients have profited by these discoveries, but not perhaps so much as has the public.

Forms of treatment other than with drugs are rapidly being developed and it is recognized that some of these methods have not received the general recognition they deserve and are not taught in the medical schools as well as is desirable. Most physicians are probably less skilled in the use of baths, diet, massage, etc., than they are in the use of drugs. And it is probable that these forms of treatment will receive full consideration before there occurs that further development of drug therapeutics for which the future seems so bright.

The important rôle drugs play in medicine is, however, frequently overlooked; it may be well to recall sometimes Naunyn's remark, that were it not for five or six drugs he would not care to be a physician at all. Surgeons especially are prone to forget the influence which drugs have had on their art. More than a century ago an eminent surgeon expressed the opinion that his specialty had almost reached the highest conceivable degree of perfection. This might have been true were it

* Address before the West Branch of the Philadelphia County Medical Society, May 14, 1909. not for the lessons of asepsis learned largely from the use of antiseptic drugs and the discovery of gèneral and local anesthetics.

The facts that there are other forms of treatment which need as careful study and teaching as that of drugs and that the field of activity of the physician in connection with the prevention of disease is ever widening are not valid arguments for neglecting drugs. They are, however, potent arguments for systematizing the study and use of the latter so that the best results may be obtained with the least expenditure of time and energy. Is this the case at the present time? An affirmative answer would imply that physicians do not begin with a handicap of ignorance and misrepresentation as to what they are using. That the profession in the past has been most shamefully imposed on in this respect is too well known to require any discussion; in the volume, "Propaganda for Reform in Proprietary Medicines," issued by the American Medical Association, will be found sufficient evidence, and the cases there quoted are only types of many.

Some seem to be under the impression that the profession is sufficiently awake to evils of the character discussed in the "Propaganda for Reform" and that deceptions such as those there exposed are no longer possible. There have undoubtedly been great improvements, but that the physician needs sources of information concerning new drugs other than the statements of those who are financially interested may easily be shown by a few examples.

It may be well to refer first to a case which has been practically settled, for the manner in which it was settled is instructive. In 1885 acetanilid, a simple chemical compound long known to chemists, was introduced into medicine. The name acetanilid is the true chemical name of the substance; it is not especially long or difficult to remember. Another name, "antifebrin," one not even suggesting the composition of the substance, was soon applied to it and has been in more or less extensive use ever since. While most physicians now know that the two names are applied to exactly the same com. pound, there was for years much confusion and cases are reported of eminent physicians who, not satisfied with the effects of "acetanilid," turned to "antifebrin." Every medical student must learn that the two are identical and it is often some time before he remembers whether antifebrin is another name for antipyrin or for phenacetin or for acetanilid. Even at present, when acetanilid has been included under its true name in most of the pharmacopeias of the world, if the physician turns to one of the leading handbooks supplied to him by the manufacturers he will find under antifebrin nothing to indicate that this is the same as the official acetanilid unless his knowledge of chemistry is sufficiently fresh for him to recognize the compound from its 
chemical formula. These two names for the same compound have already been in the medical literature of the world for nearly a generation and will continue to cause confusion and annoyance so long as the writings of this period are read.

Scores of similar cases have occurred and are occurring at the present time. New names for old drugs are often introduced in a manner to lead the physician to suppose that a new drug is being introduced. For example, I recently received a circular on "soamin" from a leading English firm. In this it is stated that "the arylarsonate 'soamin' was first introduced at the end of 190\%," and there is nothing in the circular to indicate that the same substance had been introduced by another firm several years previously under the name "atoxyl" or that the compound itself had been made in 1863 by Béchamp. A little further on in this circular I read: "The toxic symptoms noticed by continental physicians when using other arylarsonates have not been observed with soamin." As a matter of fact, most of the toxic symptoms noticed by continental writers were due to the same substance but under a different name.

The history of many of the recently introduced syntheties is the same and is about as follows: Some manufacturer discovers in a compound long known to chemists therapeutic virtues or sometimes properties which lend themselves to commercial exploitation as therapeutic virtues. The compound itself and the methods by which it is made having long been public property the manufacturer can derive profit only if he can persuade the medical profession to prescribe it under some new trade-marked or copyrighted name invented by himself. Then in a short time the same substance is put on the market by other firms whose sole contribution is a new and often misleading name; in this way there are sometimes introduced for the same compound a dozen names often as dissimilar as human ingenuity can make them. In the confusion which results really new drugs are apt to be overlooked. Thus a short time ago an eminent American physician, not being satisfied with the results he had obtained in certain cases with "atoxyl," had, upon the advice of a well-known English practitioner, been experimenting with "soamin" (with equally unsatisfactory results); neither he nor another physician whom I met about the same time had thought it worth while to try the acetyl derivative of this substance because they were under the impression that this was "about the same as atoxyl." Yet this acetyl durivative is the result of months of work by one of the master minds in medicine (Ehrlich) and certainly well worthy of a trial.

The evil results of this pernicious practice of applying many names to the same substance does not end here, however. Other manufacturers add the "new drug" to complex mixtures, inventing still more new names or, with apparent frankness, naming the mixture after some other but unimportant ingredient. In this way physicians have been led to prescribe unwittingly some powerful habit-forming drugs.

Closely connected with this question of names is another evil-the direct introduction of powerful drugs to the laity. The attitude of the medical profession in disapproving of this practice is often misunderstood. As in so many other cases, self interest is stated to be the prime cause: Lady Montagu thought physicians would oppose the introduction of inoculation for smallpox because she did not think they had "virtue enough to destroy such a considerable branch of their revenue [from treating smallpox] for the good of mankind"; now antivaccinationists state that the profession upholds vaccination for the sake of the trifling fees. Physicians discourage the use of powerful drugs by the laity for the same reasons that they advocate vaccination and other measures against the spread of contagious diseases-for the good of the public. The Council on Pharmacy and Chemistry adopted as a rule that it would not approve an article advertised to the public except in the cases of foods and disinfectants; in explanation of this rule the Council states the objection to such advertising, in part, as follows, ": . . the well-known dangers of suggesting by descriptions of symptoms to the minds of the people that they are suffering from the very diseases described the dangers of an unconscious and an innocent formation of a drug habit, and the evils of harmful self-medication, including the dangers of the spread of many infectious and contagious diseases when hidden from the physician."

One of the most effective means of inviting or encouraging self-medication is the use of catchy, often therapeutically suggestive, names. A striking illustration of the harm a layman may do himself with powerful drugs is reported in a recent number of the Lancet: A man believed he had contracted syphilis and took "soamin" in increasing doses until he was severely poisoned. The physician, called in on account of the poisoning, found no indications of syphilis. This case well illustrates one of the chief dangers of self-medication - the absence of correct diagnosis. There is no reason to believe that the firm exploiting soamin had endeavored to persuade the laity to use it without medical advice, but the use of a scientific name (sodium arsanilate, for example) would probably have prevented such misuse and would at the same time convey a definite meaning to the physician.

Many firms make a practice of using names and trade packages which will lead to the introduction of their preparations to the laity as rapidly as possible. Striking illustrations of this practice have been offered by the exploitation of preparations containing hexamethylenamin as their active ingredient. By the use of therapeutically suggestive names and circulars discussing the value of the preparations in gonorrhea large numbers of the laity have been led to believe that some of these are almost specifics for this disease-which, of course, they are not. The wrong that may be done to innocent parties from a layman believing that he is effectively treating such a disease as gonorrhea need not be dwelt on. But is the physician who brings this class of preparations to the notice of the laity by prescribing hexamethylenamin under some of these objectionable forms any less culpable than the one who makes morphin habitués or inebriates by careless prescribing? Yet physicians are doing this daily and such preparations are advertised in most of the medical journals.

The current methods of naming new drugs not only lead to great confusion but serve as a cloak for all kinds of frauds on the physician and the public. The really new remedies, and especially the really new classes of remedies, are not so numerous but that physicians could keep fairly well informed concerning them if the essential facts were presented in a simple straightforward manner. Purely commercial interests are apparently ab. solutely dominant at present, so far as the nomenclature of new products is concerned, and there is little prospect of improvement until the medical profession- 
or rather the individual physician-insists on being told, without any chicanery, exactly what he is asked to prescribe.

But it is not only in the matter of names that many of the even more prominent manufacturers do not deal entirely frankly with the physician and the public. A review of the literature bearing on proprietary medicines will readily show that the physician need not expect more detailed information from manufacturers than he actually insists on or demands.

That physicians have been content and have received but half truths concerning important matters is too well known to need much discussion. One illustration, of recent date, may, however, be given. Reference has already been made to a class of organic arsenic compounds which are attracting much attention. As they seem destined to attract still more interest in the future, and as many new compounds of the same class are being investigated, it was especially desirable that the first information given concerning them should be correct and complete. Yet the very first one, under the name atoxyl, was brought to the attention of the physician with an incorrect statement even as to its composition. Professor Pnckner, Secretary of the Council on Pharmacy and Chemistry, seems to have been the first to discover the discrepancies between the manufacturer's statement and the truth. His results were soon confirmed by Ehrlich under the following circumstances: It had been recognized for some time that this compound had certain disadvantages and Ehrlich began a systematic and painstaking search for a derivative which would have the same therapeutic properties but which would be less toxic. He saw at once that the modification he desired to make would be impossible if the statements of the manufacturer concerning the chemistry of the substance were correct. A lesser genius than Ehrlich would probably have abandoned the attempt; Ehrlich did not and soon found, as Puckner had found, that the manufacturer's statements were not correct and that it was, after all, possible to make the derivative desired. The result was the discovery of a new compound, arsacetin, which promises to be of much value.

Illustrations such as the above could be multiplied almost indefinitely, but these are surely sufficient to show that sources of information other than that supplied by interested parties are urgently needed. Were it possible for the physician to learn promptly a new drug under a single name, and be given all that is known concerning its composition and action, he would be in a much better position to begin his clinical studies; he would have more time for careful observation and for the study of the dietetic and other forms of nonmedicinal treatment. The physician's task is sufficiently complex and difficult without the handicap of confusing names and imperfect or misleading statements concerning the drugs he uses.

While the entire method of the introduction of new drugs is far from satisfactory from the standpoint of either the physician or of the public, it is but the logical outcome of the failure of the medical schools and of medical institutions to support adequate departments of pharmacology. If every important medical school had a really efficient department of pharmacology, in which properly trained men received sufficient compensation so as not to be compelled to engage in the practice of medicine or in commercial work, but who could devote all their time to teaching and investigation, giving their results freely to the world as do the chemists and physicists in the best universities, the whole aspect of the proprietary medicine question would soon change. How fruitful university laboratories of pharmacology have been in the past is sufficiently attested by the introduction into therapeutics of chloral, of antipyrin and most of the other modern antipyretics, of cocain, of paraldehyd, sulphonal and most of the other newer hypnotics, of strophanthus, eserin, the nitrites, theobromin, the suprarenal glands, and many others.

The endowment of such pharmacologic laboratories would be a good investment for both the medical profession and the public. So long, however, as they do not exist, or are so inadequately supported, the physician must pay the toll of lost prestige and the public that of high prices for new drugs, and neither has much cause to complain. And the manufacturers who make real contributions-and there are many such-have the right to expect the physician to recognize their just claims. But neither the physician nor the public is under obligations to pay toll to the parasites who simply appropriate the discoveries of other manufacturers or of physicians themselves. There are also limits to the benefits which would be reaped by even the worthy manufacturer; for many of the discoveries of the latter are such as would inevitably soon have been made by others and no one should be allowed to secure a permanent monopoly on them.

What steps can the medical profession or, rather, what steps can the individual physician take to secure the information necessary for him to derive the best results from drugs with the least expenditure of time and energy? The answer is as old as the history of medi. cine itself: by cooperation to establish and maintain standards which in the last analysis shall represent the contributions the individuals make for the common. good. Little patience is shown nowadays with those who hold up the past as a model for the present. Yet in the making and maintaining of standards for drugs the medical profession in this country does seem to have departed from one of its most honored traditions, but there are many indications that this departure is only temporary. Until comparatively recently the books of standards-or pharmacopeias-were the work of physicians; they represented the contributions of individual members. Through a variety of influences, some of which are difficult to determine but in which the low standards of medical education played a rôle, physicians took less part in the revision of the Pharmacopeia. With the diminished interest in revision came diminished adherence to standards; and then the Pharmacopeia came to represent less and less the needs of the medical profession. One of the earlier indications that this was the case was the preparation of the first edition of the National Formulary in 1888, by which the pharmacists endeavored to supply a book of standards for non-secret, in many cases elegant, preparations. But the physicians were abandoning more and more standards prepared by disinterested parties and accepting those of manufacturers, and, moreover, the works now prepared almost entirely by pharmacists failed to meet not only the fancied but often the real needs of the physician.

It is not necessary to trace the further history of this subject in detail or to relate the sporadic efforts made to counteract some of the evils resulting from proprietary medicines. A new era began about ten years ago when Dr. George H. Simmons was called to the editorship of The Journal of the American Medical Association. Dr. Simmons proved himself to be one of those-unfortunately few-editors who do not feel that their duties end with keeping the reading pages clean. As the result 
of a review of the advertising pages thousands of dollars worth of advertising was discontinued and a.firm stand taken concerning the attitude of THE Jouknal. toward proprietary medicines. This required rare courage, when there was no Food and Drugs Act, when strongly intrenched and insolent proprietary interests were threatening law suits at the least suggestion that the truth be told about their products, when the timorous feared that THE JounNaL would be wrecked, and when the medical press was hostile; but he won the battle and to-day edits the cleanest medical weekly of the world. Medical journalism does not record a more courageous course.

In the attempt to purge the advertising pages of THE JoURNAL of fraudulent products some competent and reliable authority was needed that could be referred to to decide what was right and what was wrong, especially as regards composition of the medicinal products offered to physicians. The final outcome was the formation of the Council on Pharmacy and Chemistry charged with the preparation of the book "New and Nonofficial Remedies." The purpose of this book has often been misrepresented. The authors are frequently accused of trying to dictate to the doctor or of conspiring against his freedom. The simple truth is that the American Medical Association, through the House of Delegates and Board of Trustees, has requested a number of men to serve as a committee, without remuneration of any kind, to prepare a small work on drugs which for some reason or other are not in the United States Pharmacopeia or the National Formulary. The one criterion for the admission of proprietary articles to this book is this: are they as represented; and the primary question is always, do they have the chemical composition claimed? In considering the question whether the drugs are as represented the Council is frequently confronted with a dozen preparations of the same class claiming to be "absolutely the best"; - thus there are about a dozen of the "most powerful" but "least toxic" germicides, a dozen or more of "absolutely the most powerful" diastases; quite a number of the "safest" hypnotics and so on. Evidently some of the gentlemen making these claims are mistaken and the Council has asked "to be shown." Some firms have admitted that their statements were incorrect and have changed them to correspond to the facts; others have admitted that their claims were false but stated that they would try to make products corresponding to them in the future. but that in the meanwhile they could not afford to injure their standing with the phrsicians by telling the truth; still others have stated that it is none of the physicians' business wheth. er the truth is told them or not. As a rule no further attention is paid to these latter classes of products ; occasionally one of them is exposed as an example of the kinds and varieties of frauds that are being practiced, but the Council desires its work to be constructive and not destructive.

The Council has found that there is a large and in. creasing number of physicians who desire information such as the Council attempts to collect; this desire comes partly from a fuller realization that a physician should neglect no opportunity to be certain of the composition of the drugs he uses. As a concrete example of the deception that may be practiced unwittingly I may refer to a preparation claimed to be a solution of mercuric iodid in an oil suitable for hypodermic injection in syphilis. Dr. Seidell examined a sample of this preparation in the Hygienic Laboratory; not a trace of mercuric iodid could be found. A second sample, of a lot made in the presence of a medical practitioner who weighed the mercuric iodid himself and saw it ailded to the oil, was also found to contain no mercuric iodid. We do not know in what stage of the process the drug was lost, whether by volatilization, by filtration or how; we do know, however, that it was not in the preparation which reached the physicians-as indeed the clinical results of some of the latter showed. Would not a physician who had used such a preparation in a critical case of syphilis and lost his patient feel as guilty as if he had made any other kind of a fatal mistake in prescribing, and might he not be liable in a court of law? The Council desires to give physicians information which will prevent such possibilities as this. There is a rather large number of physicians who resent having lies told to them about drugs, just as the self-respecting man in any other walk of life resents a lie. There are also those who are weary of having chemists, pharmacists, and other laymen (in one case a piano salesman) endeavoring to teach them therapeutics. There are others, again, who are becoming impatient of having the same drug presented to them under a variety of meaningless or misleading names. There is also a large number who do not care especially whether the absence of mercuric iodid, pepsin, cod-liver oil, iodin, quinin, etc., in so-called preparations of these drugs is due to incompetency or knavery but who do want some evidence of their presence in addition to that of individuals financially interested. The Council is endeavoring to make "New and Nonofficial Remedies" a work of standards for such physicians as these and it invites, as it has from the beginning, the cooperation of all.

Soon after the Council began its work an endeavor was made to arouse the antagonism of manufacturers on the ground that their property rights were being attacked. Not many of these, however, have had the hardihood to ask physicians to use their preparations and at the same time to tell them that it was none of their affairs what these contain. On the contrary, many have found it good policy not only to state the composition but to state how this may be verified by other chemists, just as the Pharmacopeia gives tests of identity and purity for the various products contained in it. I know of no physicians or editors of medical journals who deny the necessity for work such as the Council is doing. It has, however, bitter enemies. One of the leaders of these stated that it was folly to attack the Americal. Medical Association or the Council on Pharmacy and Chemistry directly; and that the only chance of check. ing the work of the latter was to attack the members personally. Dr. Simmons, as Chairman of the Council and as editor of THE JounnaL which has led in the movement, has been the subject of most frequent and persistent attack. Most of the recent ones, some of which are anonymous, can be traced directly to those who are financially interested, in one way or another, in proprietary medicines. It is scarcely necessary to consider these; a glance at the advertising pages of the medical, or rather pseudomedical, journals containing some of them, or a moment's consideration of the editors' commercial affiliations, will suffice to disclose the animus.

The incompetency or insincerity of some of the manufacturer-editors, who, till recently at least, were most persistent in these attacks and who pose as working for the uplift of the profession, may be illustrated by a concrete example which came to my attention. Dr. Seidell and I examined some time ago in the Hygienic Laboratory a number of samples of a solution of nuclein ex- 
ploited by a cornpany whose fervent appeal for a "syuare deal" is known to many of the physicians of the country. Here are a few typical statements from a circular issued at that time by the firm: "For years we have been the chief promoters of nuclein therapy, endeavoring to place its principles before the profession in the right light-in a practical, usable form and as far as possible deprived of all uncertainty. Out of our experimental work we have developed the chemistry of nuclein to a point that produces a product second to none." They stated that their nuclein was "all right;" that it had the unqualified endorsement of "hundreds and thousands" of physicians well able to judge by results; that they believed it to be far the best product on the market, etc. The following is said as to its dosage: "It should be remembered that, except in acute toxemias, over-stimulation of the cells is not to be desired; therefore, in low states of vitality, small doses (gtts. $2-5$ ), long continued, give best results. In all acute invasions of the system LARGE DOSES (gtts. $\mathrm{x}-\mathrm{xx}$, preferably hypodermically) are, however, necessary. These should be repeated at least twice daily. In emergencies, where the patient is overwhelmed with toxins, the exhibition should be made every few hours." Our examination of the solution thus described in such enthusiastic terms showed the presence of from 0.04 to 0.05 per cent. of solids (about the amount present and permitted in many potable waters). Assuming these solids to have consisted entirely of nuclein (a rather rash assumption perhaps) the usual dose of the solution recommended would have contained from $1 / 400$ to $1 / 1300$ of a grain of nuclein. If the dose were repeated about a dozen times a day the patient would in the course of a month have received nearly a grain of nuclein-an amount obtained several times over in any ordinary single meal. If the case were desperate-if, as the circular states, "the patient were overwhelmed with toxins"-and, following the directions, large doses (gtts. $\mathrm{x}-\mathrm{xx}$ ) were given hypodermically, it would have required about 100 hypodermic injections to introduce a grain of nuclein. Why not give the patient a bite of sweetbread? It would have contained as much nuclein and been more agreeable. The difference in price might be a factor; for, while sweetbreads are somewhat expensive, fifty times the price of pure gold was asked for the nuclein in this solution. The crushing reply to such suggestions would probably have been, quoting from the circular: "This nuclein is all right. It has the unqualified endorsement of our Drs. . . . as well as hundreds and thousands of others well able to judge by results." Seriously, has not such so-called clinical evidence about the value of that of physicians who a few years ago were "curing" malaria with powdered gypsum sold under the name "tasteless quinin" or of the laity who "cure" measles with sheep dung? And think of wasting valuable time in the case of serious illness experimenting with such stuff. The company exploiting this nuclein took the commendable step of practically withdrawing it from the market until they learn something about the subject; but what are the "hundreds and thousands" who obtained such good results with the old preparation doing in the meanwhile?

1. "Nuclein" has frequently been a source of confusion and mis. representation in the "literature" of proprietary medicines. In strictly scientific literature the physician reads how Loewi ad without observing any 11 effects. From this a physician would in fer that ordinarily, at least, nuclein is a harmless substance. Another proprietary preparation with the innocently sounding name "Protonuclein" was found, however, to contain considerable thyroid. There was recently placed on the market another secret proplietary product, Iodonucleoids, purporting to be a compound of
Will the medical profession allow itself to be influenced by criticisms coming from such sources as the above? And nearly all the criticisms of Dr. Simmons and of the Council have come from exactly such sources and similar interests closely allied, commercially, with them.

Before leaving this subject a word may be said concerning the attitude of many medical journals toward secret proprietary medicines. Disappointment is frequently expressed that so many of these continue to accept the advertisements of preparations which have been shown clearly to be fraudulent. It is unquestionably humiliating to see that the standards of so many medical journals, in this respect, are decidedly lower than those of some other professional journals and of many of the popular magazines. Still, an improvement is very noticeable; a sharper distinction has been made between the reading and advertising pages and severai have dropped some of the most objectionable advertisements altogether. The editors of many have become apologetic. Some say they would like to reform but will not be dictated to; like Falstaff, they will not tell the truth on compulsion. One editor remarked that some of the advertisements in his paper were so evidently frauds that nobody could be deceived! As regards those journals which are published simply as business enterprises and in. which there is a real division between the provinces of editor and advertising manager, the profession may as well accept this fact: Dishonestly exploited drugs will be advertised so long as there are doctors to use them or so long as doctors subscribe for such journals. The fact may be deplored, but it will remain a fact. The case is different with the journals supported by medical organizations. An organization which can not support a journal which is clean from cover to cover should not try to publish one at all. At present the advertising pages of the Military Surgeon, the official organ of the Association of Military Surgeons, are a striking example of what should not be tolerated in a journal controlled by a body of medical men; it is to be hoped that the new management will make radical changes.

Instances could be multiplied almost indefinitely of how secret or semisecret proprietary medicines stand in the way of progress. Many physicians in their zeal to give their patients the benefit of the latest discoveries are prescribing preparations which contain practically no medicinal ingredients at all or only the old familiar drugs under a new name. The remedy is to turn to the practice of using only those drugs, the composition of which has been determined by physicians or by their representatives.

Of the standards at present available the United States Pharmacopeia is, of course, the best. By the enactment of pure drug laws by the United States and by the several states this has practically become the national standard. Where there is the proper cooperation between physicians, pharmacists and c. ficials entrusted with the enforcement of pure drug laws the difference between the value of official and proprietary preparations is about as great as that between the legal currency and the promissory notes of Tom, Dick or Harry; those of Tom may be all right, but the probabilities are that those of Dick or Harry have not their face

iodin and nuclein. To a physician who is at all familiar with the subject of the nucleins a compound of iodin and nuclein would appeal as something new and worthy of trial. On examination, how ever, this preparation was found not to contain a true nuclein at all, but seemed to be a product such as can easily be made by simpl,
evaporating a solution of hydrionic acid with ordinary casein. 
value. Hence one of the first duties of the physician is to adhere as closely as possible to the preparations of the Pharmacopeia. A little study or consultation with one of those truly professional pharmacists who are to be found in almost every community will convince many a physician that he is using drugs for which officially recognized ones may easily be substituted. If, however, after careful study, he fails to find in the Pharmacopeia or in the case of a pharmaceutical mixture, in the National Formulary, the drug he desires to use, I believe the next best source of information is New and Nonofficial Remedies. The latter contain, in the case of proprietary preparations, not only the statements of the manufacturers, but also the results of the investigations of disinterested parties made by the authority of the American Medical Association. It is a noteworthy fact that of the several hundred preparations admitted to this book not a single one has been shown to have a composition differing from that given, whereas the larger part of the proprietary preparations at present on the American market which have not been admitted to New and Nonofficial Remedies have been found to be of uncertain or variable composition or exploited in a questionable manner. Hence a physician should be very cautious in using a drug which is not contained in one of the above-named books. If, however, after careful investigations he is convinced that he has found a drug of value which has not been admitted to these works he is false to the traditions of his profession if he does not make the fact known to his colleagues. It would be safer, however, for him first to submit his findings to the secretary of the Council on Pharmacy and Chemistry, Professor Puckner, who probably has a more encyclopedic knowledge of new drugs than any other man in the world. Professor Puckner, as secretary of the Council, has from the first requested such suggestions as well as criticisms of the products contained in New and Nonofficial Remedies. If more such requests were sent than he could answer it would pay the profession to provide additional assistants for him. The office of THE Journal of the American Medical Association should continue to be, as it is at present, a trustworthy source of information to physicians generally as well as to the members of the Association.

By far the larger number of drugs used by most physicians are those recognized by the above standards, but, on the other hand, there are not many physicians who do not use at least a few drugs of questionable character. It is the sum total of the latter which is largely responsible for the present unscientific and unsatisfactory state of drug therapeutics. Most proprietary remedies are sold at such a large profit that a comparatively few orders will keep one of them alive. If each individual physician would carefully consider the drugs he uses and then either abandon those which are not official or are not contained in New and Nonofficial Remedies, or, if convinced that they are of value, use his endeavors to get them admitted to these works (the door of the New and Nonofficial Remedies is always open for honestly. exploited drugs) much would be done to solve the proprietary medicine problem. The ideal condition will be reached only when every drug which the physician needs has been admitted to the final legal standard-the United States Pharmacopeia-and the physician should consider it one of his duties-to his patients, to his colleagues and to the public as well as himself-to use his influence to perfect and maintain this great work. The opportunity to support the Pharmacopeia comes to the physician every day; the oppor- tunity to make his influence felt in its revision comes to him but a few times in his life. One of these times is now approaching. The Convention which meets in Washington next spring will formulate the plan of the Pharmacopeia which will be the great guide for the next decade. It is the duty of every physician to endeavor to have his state medical society and his alma mater represented at this convention by three (the number each such organization is entitled to) earnest, broadminded men who will insist that, among the multitudi. nous interests seeking recognition, those of the physician and his patient will not be overlooked.

Finally, I desire to put in a plea for the support by the physician of research work in pharmacology. For thousands of years the great contributions to materia medica came from the medical profession; in the last few years only have they been coming more and more from without. The profession has lost prestige and in addition has become confronted with the proprietarymedicine problem. The solution is for the contributions to, as well as the control of, new drugs to come from the pharmacologic laboratories of the medical schools, of the Government and of medical associations. Nothing is so potent, not only for positive progress, but for dispelling darkness, as a great discovery.

\section{CERTAIN IDEALS OF MEDICAL EDUCATION \\ CHARLES S. MINOT, LL.D., D.Sc. BOSTON}

It is the function of the teacher to perpetuate, by transmission to the on-coming generation, the knowledge and traditions on which civilization is based. We who have for our share of this indispensable work the transmission of medical knowledge and of medical traditions find the difficulties of getting our freight into the depots of youthful minds always numerous and often great. We, therefore, are constantly busy with efforts to improve our transactions by selecting the most valuable knowledge to transfer, by seeking devices to quicken the business, and by trying to save the labor-waste of the students. We have, besides, to add daily to our stock all the latest novelties. Despite all these pressing demands, we must keep the whole army of data in perfect order, under the command of general ideas and of natural laws. It is inevitable that the pressure on our energies should absorb most of their power so that we are habitually too busy to pause; and yet it is , I am sure, helpful to pause occasionally to consider, not the details, not the ways and means of our business, but its underlying principles.

May I regard this hour as such a pause, which we. dedicate to an examination of the purposes of medical education and their best fulfillment? The function of a good medical school is to produce competent practitioners of medicine. I can not venture to call this an original idea of my own. Though it is a platitude to which all assent, it has its place here, in order to permit us to add that it is not the sole function of a good medical school, for only that medical school attains a high place, or even real importance, which adds on a large scale to medical knowledge and trains a steady euccession of young men to become medical teachers. Only by the active pursuit of these high aims can the influence of a medical school inspire sound professional ideals in

* Commencement Address delivered before the Medical School of Washington University, St. Louis, May 27, 1909. 